\title{
Research on the Innovation of China's Sports Vocational Education System
}

\author{
Hailong Zhao \\ Department of PE, Jiangsu Normal University (Lianyungang), Lianyungang Normal College, Lianyungang \\ Jiangsu 222006, China
}

Keywords: Chinese sports; professional sports; innovation of education system

\begin{abstract}
With the rapid development of China's social economy and the continuous improvement of the level of science and technology, the sports industry in China has also prospered. Traditional sports teaching mode fails to meet the needs of sports development in the new era. In order to promote students' personalized development in physical education, teachers need to constantly reform and innovate sports teaching methods. Different schools will use different teaching methods when promoting the physical education teaching. Each teaching method will bring different teaching effects. In this paper, the author takes professional sports as a breakthrough point, actively explores the necessity of physical education, and gives the adequate solutions according to the related problems [1].
\end{abstract}

\section{Introduction}

Compared the sports discipline and other disciplines, with special nature of sports teaching are presented in front of students in classroom teaching, classroom teaching time is more effective, unable to complete the task of teaching a large number of provisions in the short period of teaching. Different students because of life experience and physical qualities have great difference, so also have different problems in the process of sports learning, schools should make rational teaching plan according to the different learning characteristics of different students, in order to maximize the increase of physical education in our country occupation education effect [2].

\section{The necessity of the innovation of China's sports vocational education system}

In the sports teaching in our country, many schools and teachers are accustomed to using the relevant teaching ways of training a single, this will make the homework burden of students increased to a certain extent, the students did not have too much can own use time, can not in the learning process of students will be very good their personality and learning potential, a long time is not conducive to the development of good physical and mental health of students. In order to make the development of China's sports vocational education conform to the trend of development in today's era, we should constantly pay attention to cultivating students' learning ability and innovative consciousness in physical education. The sports occupation education Chinese, all their energy for the employment of many school students, school students concern over the employment rate, resulting in the process of teaching for PE course teaching has been neglected, thus not conducive to the all-round development of students.

\section{The innovation of China's sports vocational education first is the innovation of the concept}

In promoting the teaching of sports vocational education, we should adhere to the idea of "people-oriented" and "health first". The so-called health oriented physical education teaching thought, is actually the emphasis should put health education into the sports teaching, in order to improve the health and health maintenance work will extend to the whole range of sports teaching, the sports service and the concept of health can be implemented to work every aspect of physical education. And adhere to the people-oriented idea is to respect the initiative of students fully in 
physical education, students should be able to follow the advice of learning in the teaching process, how to communicate and exchange with the students, to provide students with the most satisfactory service in sports teaching[3].

The purpose of the recommendation of physical education is not to help the students to strengthen the body, but more importantly, to touch the healthy development of the students' heart. If you want to promote the harmonious development of students' body and mind learning learning, so only rely on the classroom teaching of physical education is not to achieve, which means that physical education teachers need to focus on the teaching of sports skills to the students, and be good at cultivating students' PE learning habits and learning consciousness. In the work of sports occupation education need to let the students know the meaning of sports fundamentally, make the students to establish correct sports learning attitude and clear learning objectives, but also according to the teacher's teaching and guidance for their sports learning target continuous efforts. In the whole teaching process, we also need to help students master adequate fitness skills, and use scientific and reasonable teaching methods to help students keep exercising, and cultivate students' ability to enhance their fitness and cooperation [4].

\section{Some practical suggestions on the innovation of China's sports vocational education system}

The practical nature of certain sports this course in the teaching work, students need in learning sports consumes a lot of energy, and physical education are a lot of time outdoors, outside bad weather often brings a physical burden for students, not cold weather will lead to good many students do not want to go out. While in the physical teaching, if teachers simply teach action sports related to the students, so long time will make students feel dull as ditch water learning atmosphere, thus losing the learning interest in sports learning, no interest in learning can cultivate sports learning and innovation ability. In order to sports teaching classroom atmosphere can be better if you change the dull as ditch water, promote the teaching work should be appropriate to the use of "joyful sports teaching means, which means for students to create a relaxed and pleasant learning atmosphere and sports for students to feel the charm of learning sports, under this kind of teaching mode, students' learning sports rely on their own interest, and the related sports teachers will be based on the students' personality for students" suitable for the development of the learning plan, let the students sports knowledge in the course of the game to learn in happiness. In this process, teachers should fully grasp the characteristics of the actual age of the textbooks and students, also can properly use the outside temperature changes and game activities rich and colorful, for students to start with some outdoor games they practice learning situation, guide and encourage students to actively participate in them, so as to enhance the learning interests of physical education and the enthusiasm to participate in sports activities of students. Now the transformation of physical education and traditional physical education the biggest difference is that the main body, under the traditional teaching mode, teachers excessively placed himself in the process of teaching status, teaching methods are mostly teachers blindly explanation, students passively accept, students on sports learning all of the teachers thought. However, under the innovative sports teaching mode, teachers are good at finding out the shortcomings of students in sports learning process, and are also willing to communicate with students in a timely manner. In the way of teaching, teachers should give students full thinking to create space, and can enlighten students in the relaxed space. In the organization of teaching education is supposed to be free and happy teaching methods, the ideal teaching effect can be interesting teaching and seriousness of the combination of teaching, in the use of this kind of teaching methods, to promote the benign interaction between teachers and students and emotional communication[5].

Sports is a special kind of culture and art, many sports movements are the skills of art movements, teachers should be to cultivate students' aesthetic ability from the perspective of aesthetics when students learn the sports action, prompting students from heart deep sense of sports in the process of sports learning in the wonderful, which can enhance the students the ability to create beauty. When teaching is going on, teachers can rely on multimedia power to show students a lot of sports action pictures and sports action videos, which can help students to watch the video and 
develop students' analytical ability and logical thinking ability. In the sports learning process, some sports knowledge is quite abstract, if simply according to the teaching content of the teaching objectives of teaching, some abstract knowledge can not be students to grasp the profound, but if the use of appropriate teaching aids, will be able to abstract teaching knowledge becomes more vivid and specific, convenient and students to master. After watching the video and to teach students some sports theoretical knowledge, teachers should lead students to practical operation training, in the actual operation of training process, should give full play to students' autonomous learning ability, all the action after the completion of the students themselves through self summary, summary can well grasp the shortcomings of their own. Giving the initiative of sports learning to students themselves can not only help students master a lot of theoretical knowledge of physical education, but also improve their creativity in sports learning [6].

Sports itself is a discipline with a wide range of subjects. When training, some students can finish their actions by hand, but some of them need to be equipped with sports equipment. With the training action, many devices are based on adult standards, a large part of the mechanical action does not belong to the middle school or lower age students, sports equipment is expensive, sports can not guarantee every student in the hands of time to have sports equipment, in this case, the teacher should according to the needs and issues of knowledge teaching, guide students to produce their own sports equipment or transformation of some sports equipment, when students do it yourself time to be able to stimulate their creative ability. The emergence of sports events is mostly due to the creation and invention of the body according to the conditions and ideas of the time, which proves to some extent that sports can happen at any time and anywhere. By fully utilizing the characteristics of physical education, teachers can properly guide students to create inventions, and at the same time, perfect combination of actual production practice activities and folk activities.

In the process of daily life and learning, people must need to exercise. Reasonable exercise can make the body's metabolism become more and more vigorous, so as to promote the development of human tissue and skills, and effectively enhance and maintain the body's function and health. According to the relevant data, it shows that many scientists and working people do not pay enough attention to proper exercise because of their daily transition. They will cause various kinds of physical diseases. If they are serious, they will also threaten the health and safety of life. In the course of school running, it can not guarantee the sustainable development without proper setting up of physical education course. The teacher in the classroom teaching so that students fully in my body motion theory and technology is an essential teaching work, through mastery of reason and skills fully can improve exercise ability, but also the formation of lifelong exercise after the good exercise habit, ultimately achieve the ideal target of PE teaching.

In order to better improve students' sports learning level and innovate their vocational education system, the most important problem is that teachers should do well in pedagogical guidance methods. Teachers can use appropriate learning tips to inspire students' physical education learning thinking, can also be used to discuss the modern teaching methods and means, to guide students to explore the connotation of sports learning, to broaden their horizons in sports learning during the exploration process, help students to grasp more rich sports culture, so as to improve the students' PE learning subject consciousness. When teachers are teaching, they must pay attention to training their confidence in sports learning. This means that relevant physical education teachers need to make different teaching methods according to different students' learning conditions, and make correct guidance to students. Each of the students learning in sports, because the technology generated by the different learning effect is different, the use of individualized physical education goals, to make every student learning all have achieved in sports. In addition, encouraging teaching evaluation should also be adopted. Encouraging language can help students enhance self-confidence and enable students to feel their sense of existence from the bottom of their hearts. Encouraging teaching is a necessary way to cultivate students' innovative spirit. In fact, when students are learning sports, teamwork spirit is also essential. Solidarity and cooperation between students and students can improve the efficiency and quality of sports learning.

The system of physical education occupation change is from the end of the original evaluation to 
the whole process of evaluation now, past the traditional sports evaluation purpose is mainly to standard, this evaluation of the test results is not scientific and high strength, but also to a certain extent reflect the students in one stage of the process of sports learning ability. The mode of sports teaching evaluation system in innovation under this evaluation not only pay attention to students' achievement, and to save all the view of evaluation of physical education, in sports teaching should include mutual evaluation evaluation of the evaluation of teachers and students and students and link time in the evaluation activities, teachers should set up scientific and reasonable evaluation content, not only contains the physical testing of students, and need to be included on students' physical tests, after all the testing and evaluation of the skills of the students also need to target the final summary. Nowadays, the content design of the sports evaluation system is not too much to pay much attention to the students' achievements. The key point of the evaluation is the teaching goal of the whole physical education process. The evaluation system of physical education can provide a comprehensive analysis and summary for students' sports learning, and at the same time, it can form formal affirmation for some hard working students, and help students establish confidence in sports learning.

\section{Conclusions}

In general, the reform of sports classroom teaching should strongly advocate innovative education, while schools should respect students' personality development needs when implementing innovative teaching mode. Students' innovative thinking ability and innovative thinking habit need to be formed under the correct learning mode. Teachers should pay attention to the cultivation of students' independence and creativity in every teaching link. The sports teaching teachers need to have a strong sense of innovation and sense of responsibility, and to implement practical teaching methods according to the actual situation of sports teaching, the only way to maximize the innovation of sports occupation education system, improve the student's learning level.

\section{References}

[1] Stewart V. Made in China: challenge and innovation in China's vocational and technical education system [J]. 2015.

[2] Stewart V. Made in China: Challenge and Innovation in China's Vocational Education and Training System. International Comparative Study of Leading Vocational Education Systems. [J]. National Center on Education \& the Economy, 2015.

[3] Xiao Y M, Mao-Rong L I. On the Reformation and Innovation of Vocational Education Management System in China [J]. Journal of Jiangxi Normal University, 2005.

[4] Jiang J, Zhang L. Research on the Innovation of Vocational Education Management System[C]// International Conference on Education, Sports, Arts and Management Engineering. 2016.

[5] Guo S W. Reflection on Integration of Vocational Education and Industry under the Chinese Innovation-driven Development Context [J]. Vocational Education Research, 2015.

[6] Yang Y L, Yang J, School V E. A Research of the Innovation of Higher Vocational Education Management System in China [J]. Journal of Jilin Teachers Institute of Engineering \& Technology, 2014, 378(32-33):2436-2442. 